\title{
THE USE OF THEOCALCIN IN THE TREATMENT OF HEART FAILURE OF THE CONGESTIVE TYPE
}

\author{
BY HAROLD J. STEWART
}

(From the Hospital of the Rockefeller Institute for Medical Research, New York, N. Y.)

(Received for publication October 16, 1929)

In cardiac therapy, usually, one is ultimately confronted with a state in which the condition is not alleviated by the measures which we now have for treating it. This is particularly the case in the treatment of patients suffering from heart failure, who are exhibiting edema, ascites and hydrothorax. It remains for future study to define the conditions which regulate the effectiveness of a diuretic (including digitalis) at one time and its ineffectiveness at another, as well as to define the types of heart failure (classified on an etiological, physiological or anatomical basis) which are likely to respond to certain measures, if there is any distinction to be made on this basis.

For several years we have been studying theocalcin (Merck) in the treatment of patients suffering from heart failure of the congestive type. Because the drug appears to be useful in the treatment of this condition and also because of the absence of reports of its use in the literature in this country, we are reporting our experience with it.

Theocalcin is a trade name for theobromine-calcium salicylate. It is said to contain 11 per cent calcium, 48 per cent theobromine, and 38 per cent salicylic acid. It is composed of 1 atom of calcium combined with 1 molecule each of theobromine and salicylic acid. There are two interpretations of the nature of the combination. One is that its chemical structure is $\mathrm{C}_{7} \mathrm{H}_{8} \mathrm{~N}_{4} \mathrm{O}_{2} \cdot \mathrm{C}_{6} \mathrm{H}_{4} \mathrm{CO}_{3} \mathrm{Ca}$. On the other hand, New and Non-Official Remedies ${ }^{1}$ states that it is a double salt or mixture of calcium theobromine, $\left[\mathrm{C}_{7} \mathrm{H}_{7} \mathrm{O}_{2} \mathrm{~N}_{4}\right]_{2} \mathrm{Ca}$, and calcium salicylate, $\left[\mathrm{C}_{7} \mathrm{H}_{5} \mathrm{O}_{3}\right]_{2} \mathrm{Ca}$. In Europe it is distributed under the name of calcium-diuretin. Since the introduction of the drug many papers reporting its use have appeared; the emphasis of these, however, has

' J. Am. Med. Assoc., 1925, lxxv, 975. 
been placed on the use of the drug in states of arterial hypertension (Basch (1), Kaiser (2), Askanazy (3), Matthes (4), and Fahrenkamp (5)). Selig (6), however, has published reports concerning its effect on the volume of urine excreted. He found that it induced diuresis. Since there are in the literature no other reports of the diuretic properties of this drug, we have given it to a few patients in order to gain an idea of its effectiveness in heart failure of the congestive type, but we have not attempted in all cases to compare its action with that of other diuretics, although it has been possible to do so in several instances. Even in the absence of extensive comparative data, we are able to draw certain inferences about the relative effectiveness of this drug.

\section{METHOD OF INVESTIGATION}

All the patients were resting in bed. With one exception (case 6, who was on a salt free diet) they were taking ward diet, free of salt except that used in cooking. The intake of fluid was limited to 1200 cc. a day, although in the case of one patient (case 12) it was only $1000 \mathrm{cc}$. With all patients there was a control period of observation before the drug was given. When the administration of theocalcin was combined with that of digitalis it was done in the following manner: If theocalcin had been given first it was discontinued for a few days; digitalis was then given; after the effect of this had been established, theocalcin was again given provided diuresis had not occurred.

Theocalcin was administered in doses of 1.0 to 1.5 gram three times a day usually at $9.30 \mathrm{a} . \mathrm{m}$., at 1.30 p.m., and at 4 p.m. The first day the patient received the smaller amount to guard against over-dosage in the event of an idiosyncrasy to the drug. The dosage of 3.0 or 4.5 grams a day was maintained as long as diuresis continued.

\section{OBSERVATIONS}

Sixteen patients suffering from heart failure of the congestive type received the drug. To 14 it was given in sufficiently large doses and its administration was sufficiently well controlled to permit of no doubt about its effect. In one patient (case 15) nausea and vomiting forced discontinuance after one day; in another (case 13) it is not possible to separate the effect of theocalcin from the simultaneous action 
of digitalis and urea. It was also administered to one patient (case 17) without signs of congestion to ascertain its effect in the absence of edema, as well as to a second patient (case 18) exhibiting edema and ascites of nephritic origin, to test its action in this condition.

In addition to the usual hospital graphic records (temperature charts, fluid-intake and -output and weight sheets, and blood pressure sheets) in the case of each patient all the data were combined in special large charts. ${ }^{2}$ On these charts were also recorded daily by means of symbols the clinical signs and symptoms and the changes which occurred in them in the course of treatment (fig. 1).

Case 1. D. T. S., Hospital No. 6443, a man aged 65 years, suffering from a first attack of heart failure of the congestive type, complained of shortness of breath of 2 years' duration, which had increased in severity in the last 6 months. Edema of the extremities had been present for 2 months. Cyanosis and dyspnoea were present. The lungs were congested. Right hydrothorax, edema, marked ascites and enlargement of the liver were present. Diagnosis: ${ }^{3}$ Etiological: arteriosclerosis; Anatomical: cardiac hypertrophy, mitral insufficiency, right ventricular preponderance (probably due to torsion of the heart because of the presence of funnel chest); Physiological: transition of 2:1 auricular flutter to auricular fibrillation on the administration of digitalis, heart failure of the congestive type.

Under a regime of rest and $1200 \mathrm{cc}$. of fluid a day, the edema of the legs decreased slightly, although the volume of urine remained between $480 \mathrm{cc}$. and $885 \mathrm{cc}$. per day and the weight increased (fig. 1). After a control period of 5 days he was given theocalcin 3.0 grams the first day followed by 4.5 grams a day. Diuresis occurred at once with a maximum daily output of $2290 \mathrm{cc}$. The patient lost $8.4 \mathrm{kgm}$. in a 12 day period and cyanosis and dyspnoea became less, râles were no longer heard, the edema, ascites and pleural effusion disappeared and the liver became smaller. Then a discontinuance of theocalcin was followed by a fall in urine output to $470 \mathrm{cc}$. and a gain in weight. Theocalcin was resumed and the output increased and varied between $950 \mathrm{cc}$. and $1200 \mathrm{cc}$. a day. Theocalcin was then discontinued. Because of rapid cardiac rate and an enlarged heart we decided against the use of quinidine. He was given digitan 1.0 gram within 24 hours which resulted in a urinary output of $2400 \mathrm{cc}$. when it was at a maximum. During this time, however, there were no signs of congestion that could be detected on physical examination. 2:1 auricular flutter persisted. After giving additional

${ }^{2}$ These special charts are made of all patients admitted to the cardiac service. They are printed for us by Corlies Macy and Co., New York.

3 The diagnoses in this paper conform to the nomenclature for cardiac diagnosis recommended by the American Heart Association. Am. Heart J., 1926-27, ii, 202. 


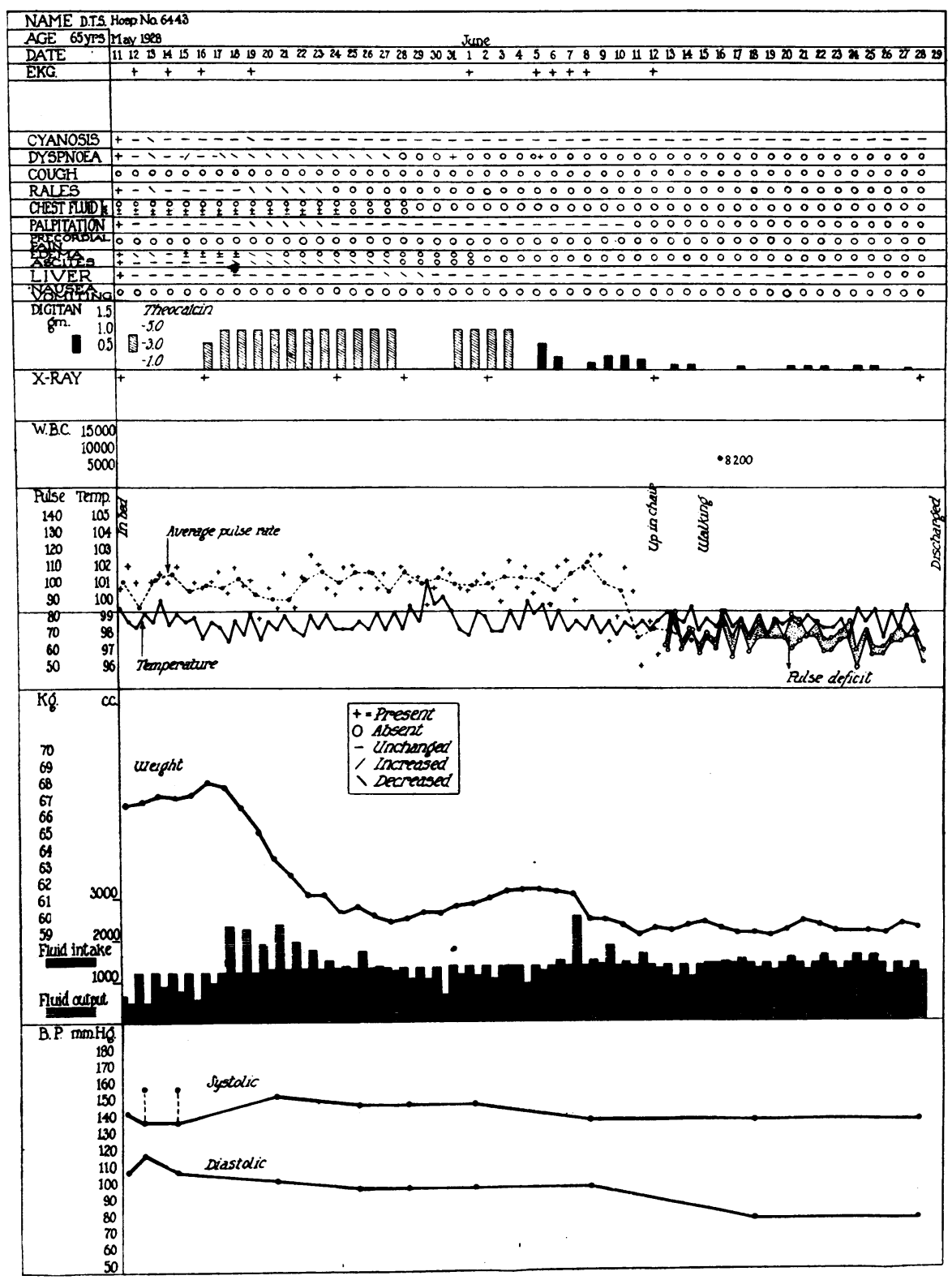

Frg. 1. In this figure is reproduced the "cardiac chart" of case 1. Diuresis occurred following the administration of theocalcin as well as after giving digitalis. The highest and lowest pulse rates for the day are indicated by "+" marks, the average pulse rate being shown by the broken line. After the administration of digitalis the rhythm of the heart which had been 2:1 auricular flutter changed to auricular fibrillation; when this occurred the ventricular heart rate was counted at the apex simultaneously with the radial pulse rate and the corresponding "pulse deficit" charted. The daily change in the signs and symptoms of heart failure was recorded by meansof the following symbols: $+=$ present; $-=$ unchanged; $0=$ not present; $\backslash=$ decreasing and $/=$ increasing. 
digitalis the rhythm changed to auricular fibrillation and the ventricular rate became slower. While taking small doses of the drug he was discharged in excellent condition, but was advised to continue taking digitalis.

Theocalcin therapy was accompanied by excellent diuresis, and the patient became free of the signs of heart failure. Later, when taking digitalis, increase in the volume of urine also occurred.

Case 2. P. R., Hospital No. 5584, a man aged 44 years, was suffering from a first attack of heart failure. He complained of shortness of breath of 2 months' duration, and edema of the extremities for 2 weeks. There was marked cyanosis

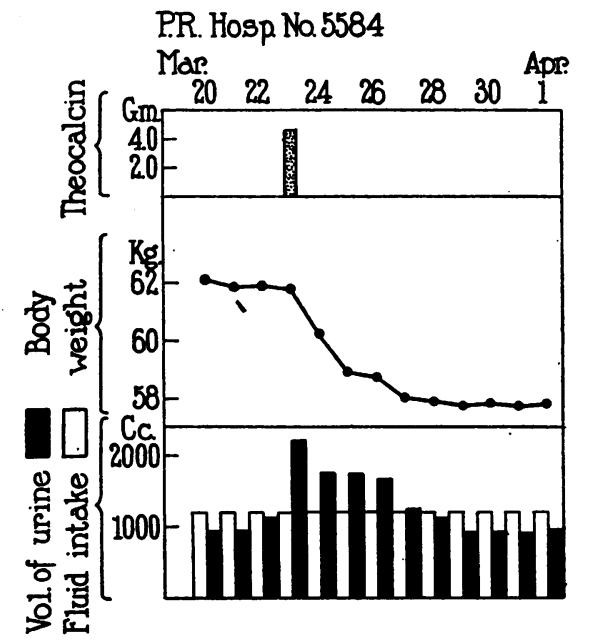

Fig. 2. In this figure, as well as in figures $3,4,5,6$, and 7 , is shown the effect of giving theocalcin upon increasing the output of urine together with the corresponding loss of weight in cases $2,3,4,5,6$, and 14 respectively. The etiology of the cardiac disease in cases 2 to 6 inclusive was presumably arteriosclerosis, while that in case 14 was rheumatic fever.

and dyspnoea, together with edema of the extremities, ascites, enlargement of the liver, right hydrothorax and pulmonary congestion. The systolic blood pressure measured $90 \mathrm{~mm}$. of mercury, the diastolic $60 \mathrm{~mm}$. Diagnosis: Etiological: arteriosclerosis; Anatomical: chronic myocarditis, cardiac hypertrophy, mitral insufficiency, aortic insufficiency, left ventricular preponderance; Physiological: normal sinus rhythm, heart failure of the congestive type. He improved slightly while resting in bed and taking $1200 \mathrm{cc}$. of fluid a day and in 12 days lost $3.2 \mathrm{kgm}$. in weight; but the output of urine was not more than $1100 \mathrm{cc}$. per day. His condition then became stationary; but after a total dose of 4.5 grams of theocalcin on one day, there was diuresis of $2109 \mathrm{cc}$. and a loss of $1.6 \mathrm{kgm}$. in weight (fig. 2). 
Although the drug was given on one day only, diutesis continued for 5 days longer and resulted in 6 days in a loss of $4.1 \mathrm{kgm}$. All signs of heart failure disappeared, with the exception of fluid in the right pleural cavity. He then gained $1.0 \mathrm{kgm}$. but following the administration of theocalcin 4.5 grams a day for 3 successive days, a slight increase in the volume of urine occurred. Then digitan 1.0 gram was given without inducing diuresis; but because the ventricular heart rate became slower we continued to give it in small doses. Fluid was removed from the right pleural cavity by paracentesis. Theocin and later diuretin were given without any increase in volume of urine but later when he was taking theocalcin 2.0 grams the daily output of urine was sufficient to prevent recurrence of the signs of heart failure. He was therefore advised to continue its use after discharge.

In this patient therefore the administration of theocalcin was followed by excellent diuresis.

Case 3. W. S., Hospital No. 6098. The patient, a male aged 55 years, was admitted to hospital suffering from a second attack of heart failure. The first attack had occurred 1 year previously. The signs and symptoms of failure were dyspnoea, cyanosis, pulmonary congestion, right hydrothorax, marked ascites and marked edema. The systolic blood pressure was $120 \mathrm{~mm}$. of mercury, the diastolic $90 \mathrm{~mm}$. The heart was enlarged; there was a systolic murmur at the apex; the rhythm was that of auricular fibrillation. The Wassermann reaction of the blood was negative. Diagnosis: Etiological: arteriosclerosis; Anatomical: cardiac hypertrophy: mitral insufficiency, slight right ventricular preponderance; Physiological: auricular fibrillation, heart failure of the congestive type.

The patient had been treated one year ago in this hospital during the first attack of failure. Diuresis then occurred promptly while he was resting in bed taking 1200 cc. of fluid a day and a diet free of salt except that used in cooking. He became entirely free of the signs and symptoms of heart failure by these measures alone. Later when there were no signs of heart failure of the congestive type he was given theocalcin without diuresis. Later still, because of the presence of auricular fibrillation with rapid ventricular rate, he was given digitalis without an increase in the volume of urine; increase was not to be expected, however, since no signs of congestion could be detected. The ventricular rate, however, became slow. He was then given small doses of digitalis which he continued to take regularly after leaving the hospital. He remained well for 1 year working at his trade as a baker. Signs of heart failure then appeared suddenly within 24 hours and increased in severity in a very few days, hence he was readmitted to hospital. With a fluid intake of $1200 \mathrm{cc}$. a day the volume of urine remained low and his weight increased. He was then given theocalcin 4.5 grams a day; remarkable diuresis began at once; on the second day the output was over 4700 cc. and there was a corresponding fall in weight (fig. 3). The drug was continued 6 days more during which diuresis persisted and the patient became free of the signs and symptoms of heart failure. The loss of weight amounted to $12.7 \mathrm{kgm}$. 
The administration of theocalcin to this patient induced striking diuresis and by this means he was made free of the signs and symptoms of heart failure.

Case 4. I. P., Hospital No. 6339 . The patient, a woman aged 65 years had suffered from 4 attacks of heart failure within 15 months, for each of which she

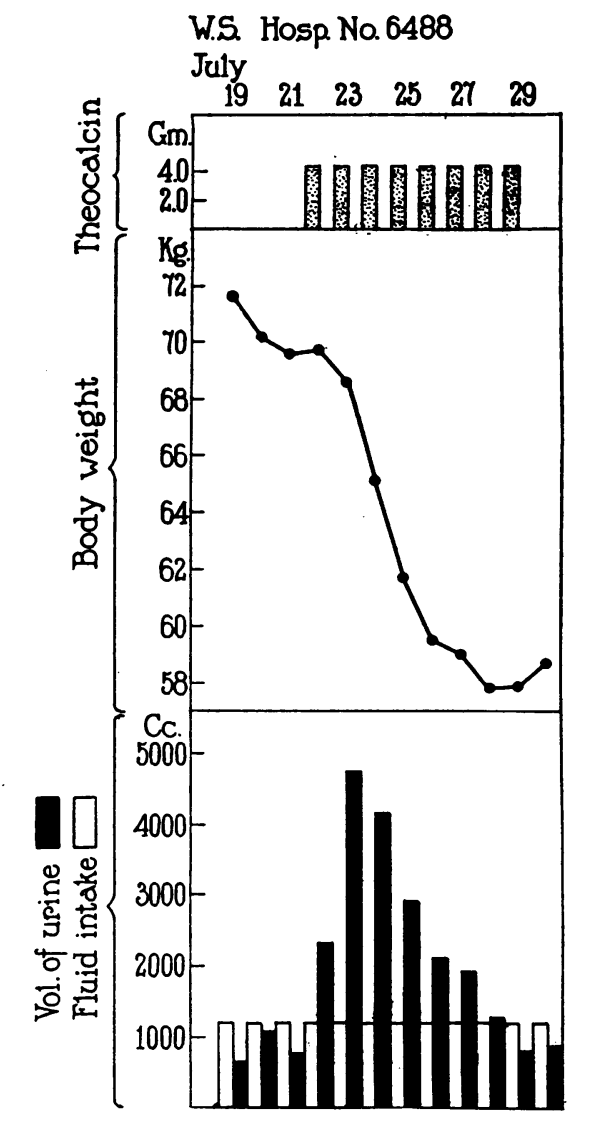

Fig. 3. Effect of Theocalcin in Case 3

See legend of figure 2

had been treated in this hospital. Dyspnoea, cyanosis, marked edema, ascites, enlargement of the liver, and a localized hydrothorax between the upper and middle lobes of the right lung (Stewart (7)) were all present. The systolic blood pressure measured $130 \mathrm{~mm}$. of mercury, the diastolic $100 \mathrm{~mm}$. Diagnosis: Etiological: arteriosclerosis; Anatomical: cardiac hypertrophy, aortic roughening, 
mitral insufficiency, chronic myocarditis, left ventricular preponderance; Physiological: auricular fibrillation, heart failure of the congestive type.

From the onset of this, the fourth, attack of heart failure until admission to hospital the patient had been given digitalis. Diuresis did not occur. The ventricular rate was slow. While resting in bed and taking $1200 \mathrm{cc}$. of fluid a day, the output of urine remained low (185 cc. to $385 \mathrm{cc}$. a day) and she continued to gain weight. On the fourth day after admission she was given theocalcin 3.0 grams (fig. 4). The output of urine rose to $1065 \mathrm{cc}$. She was then given theocalcin 4.5 grams a day. The volume of urine continued to increase, amounting to a maximum of $2725 \mathrm{cc}$. a day. In the 10 days the drug was given she lost 7.3 kgm. The signs of heart failure diminished conspicuously. At this time the drug was however becoming less effective and hence was discontinued. After an interval of 24 hours she was given digitan 1.2 gram because the ventricular rate had become more rapid and she complained of palpitation. Although the ventricular rate became slower, diuresis did not occur; gain in weight continued as the output of urine decreased to 300 to $400 \mathrm{cc}$. a day. When theocalcin was given again an increase in the volume of urine promptly occurred, amounting to $1925 \mathrm{cc}$. at its maximum; so that in a 9 day period she lost $6.6 \mathrm{kgm}$. The liver could then no longer be felt and edema and ascites were very much diminished. Digitalis sufficient to keep the ventricular rate slow was continuously given. When theocalcin was omitted for 2 days the output decreased and the weight increased. On resuming the drug diuresis began on the third day, the output reaching $1815 \mathrm{cc}$. For the next 8 days the output remained satisfactory and she lost $6.8 \mathrm{kgm}$. in weight. There was almost no edema, only slight ascites, and cyanosis and dyspnoea became less. Since theocalcin was now less effective it was not given on the next two days. Meanwhile ventricular premature contractions were occurring frequently and finally paroxysms of ventricular tachycardia appeared. The patient became rapidly worse. Theocalcin was now without effect. The rapid ventricular rate could not be controlled either by the omission of or by the administration of digitalis; nor did the administration of quinidine have an effect on the paroxysms of ventricular tachycardia; the rapid ventricular rate continued. The patient became steadily worse and died.

In the treatment of the first 3 attacks of cardiac failure diuresis occurred when digitalis was given, but in the fourth attack, it was without effect. In the terminal attack, on the other hand, the administration of theocalcin was followed by diuresis on three occasions, even when the drug was given for periods as long as from 9 to 18 days.

Case 5. J. L., Hospital No. 6388, was a male aged 53 years who complained of dyspnoea and edema of 6 weeks duration. He had suffered from 8 attacks of heart failure in 2 years. The signs were cough, cyanosis, pulmonary congestion, right hydrothorax; edema, ascites and enlargement of the liver. The systolic blood pressure measured $140 \mathrm{~mm}$. of mercury, the diastolic $100 \mathrm{~mm}$. Diagnosis: 


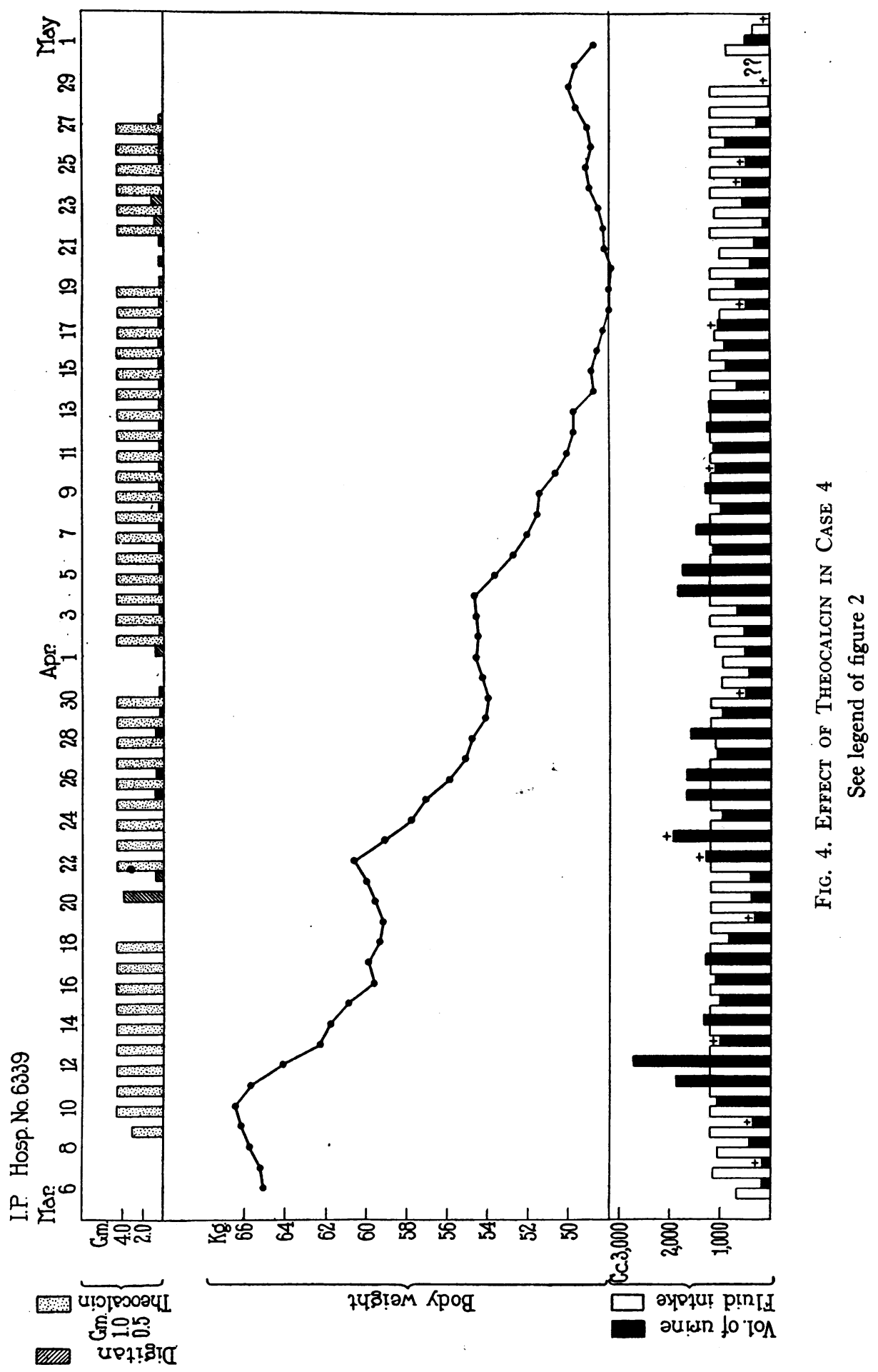




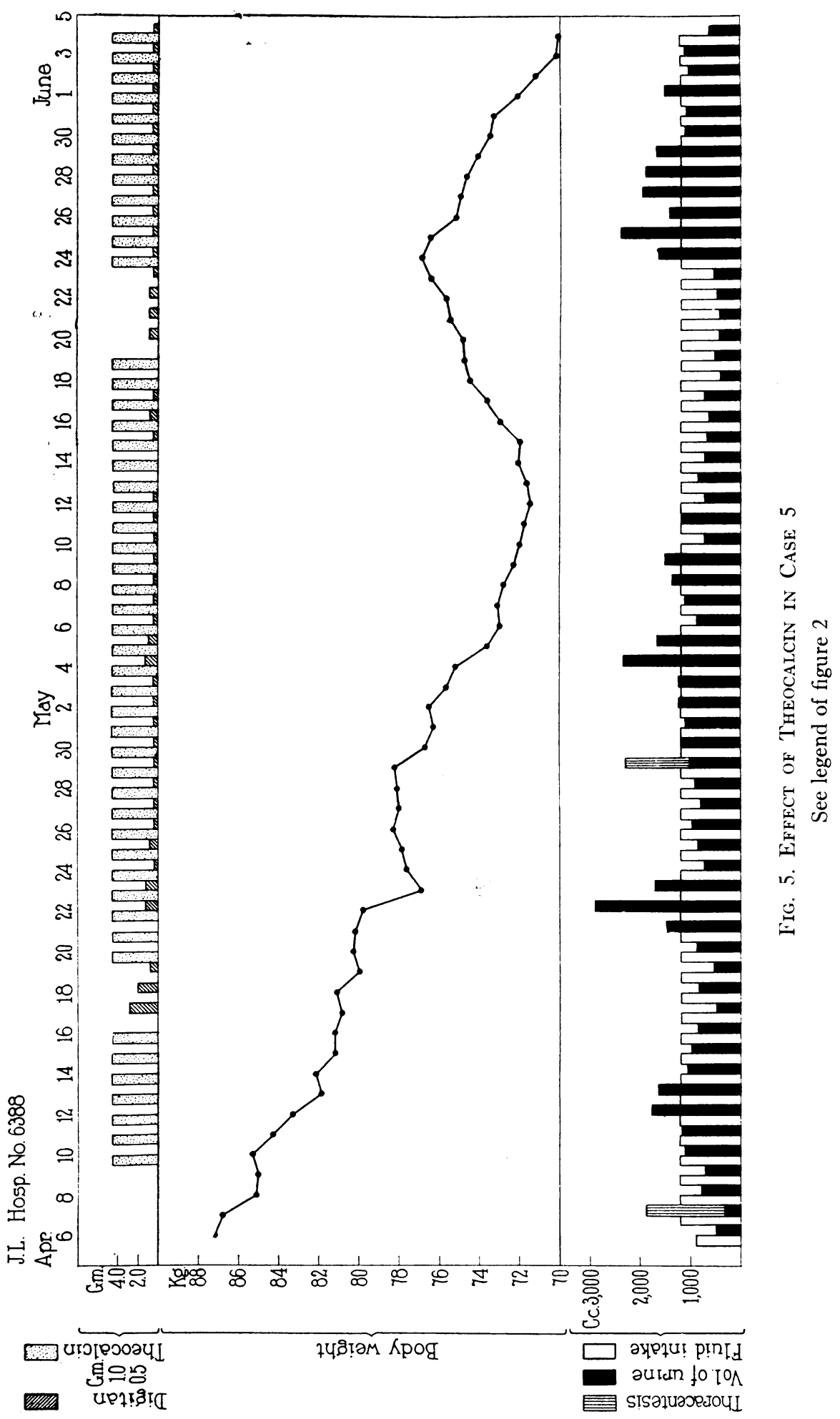


Etiological: arteriosclerosis; Anatomical: cardiac hypertrophy, chronic myocarditis, left ventricular preponderance; Physiological: normal sinus rhythm, right intra-ventricular heart block, heart failure of the congestive type.

The fluid intake was limited to $1200 \mathrm{cc}$. a day. The patient was so breathless that it was necessary to aspirate fluid at once from the right pleural cavity. During the first 4 days in hospital he did not improve. The volume of urine varied between $325 \mathrm{cc}$. and $796 \mathrm{cc}$. On taking theocalcin 4.5 grams a day diuresis occurred and the output reached $1780 \mathrm{cc}$. per day (fig. 5). In a 7 day period he lost $4.4 \mathrm{kgm}$.; the edema and ascites diminished. He was then given digitan 1.4 gram within 36 hours without diuretic effect. Meanwhile there was a sudden rise in temperature and the count of the white blood cells amounted to 33,000 per cu. $\mathrm{mm}$. due to severe cellulitis of the tongue. When the rhythm of the heart changed to auricular fibrillation digitan 1.3 gram was given to keep the ventricular rate slow. Theocalcin having been omitted for 3 days, was given during 23 days. The volume of urine increased to $2922 \mathrm{cc}$. a day. The patient lost $8.8 \mathrm{kgm}$. Edema and ascites disappeared. During this period fluid was once again removed from the right pleural cavity by paracentesis. Theocalcin, although it was less effective, was continued 8 days longer while the output varied between $700 \mathrm{cc}$. and $800 \mathrm{cc}$. a day. In spite of the reversion of the heart beat to a normal rhythm and the continued administration of digitalis, the patient gained weight. When theocalcin therapy was discontinued the output fell to $400 \mathrm{cc}$. to $500 \mathrm{cc}$. a day, slight edema reappeared and the amount of fluid in the right pleural cavity increased. On resuming its use, however, diuresis promptly occurred, to the extent that the output reached $2400 \mathrm{cc}$. a day and in 9 days the patient lost $4.7 \mathrm{kgm}$. in weight. Edema again disappeared. Later when it became less effective it was discontinued. Pulmonary congestion recurred. Novasurol 1.0 cc. was then injected intramuscularly. as a test dose, followed 2 days later by an injection of $2.0 \mathrm{cc}$. Accompanying the larger dose the output rose to $3852 \mathrm{cc}$. and the patient lost $3.6 \mathrm{kgm}$. in weight. The following day the output fell to $560 \mathrm{cc}$. When a like amount of novasurol was injected 2 days later the output increased only to $1922 \mathrm{cc}$. From that time he was given novasurol every 2 or 3 days and theocalcin on the alternate days. In this way the output was sufficiently large so that the reaccumulation of fluids did not take place.

The administration both of theocalcin and of novasurol to this patient induced a degree of diuresis sufficient to free him of the signs of heart failure.

Case 6. N. T., Hospital No. 5817, was a male aged 58 years who was admitted to the hospital complaining of shortness of breath for 1 year, edema for 1 year, and ascites for 1 to 2 months. There were dyspnoea, cyanosis, right hydrothorax, pulmonary congestion, edema, ascites and enlargement of the liver. The systolic blood pressure measured $120 \mathrm{~mm}$. of mercury and the diastolic $85 \mathrm{~mm}$. Diagnosis: Etiological: arteriosclerosis; Anatomical: cardiac hypertrophy, chronic myocarditis, mitral insufficiency, left ventricular preponderance; Physiological: normal 


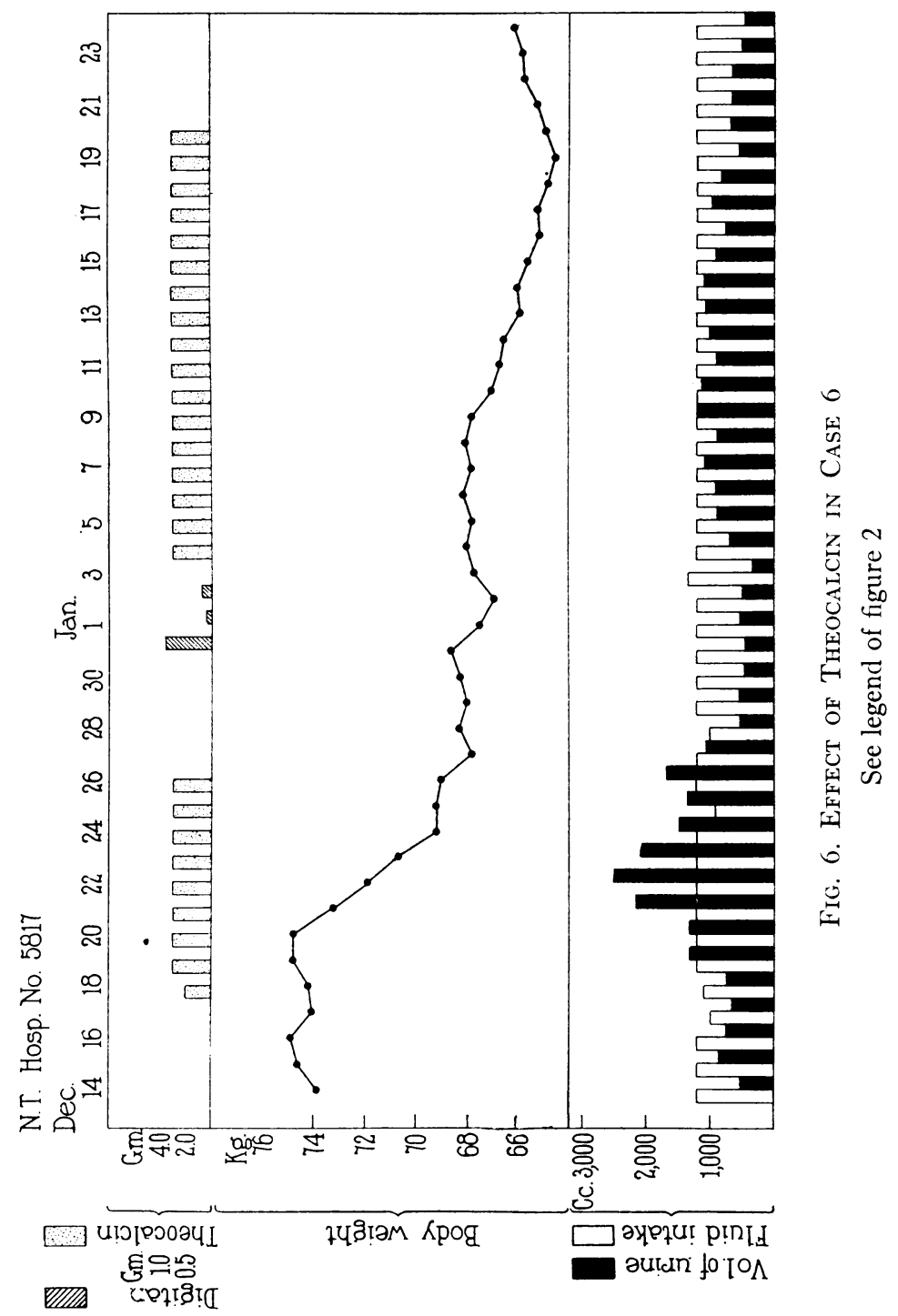


sinus rhythm, prolonged conduction time, auriculo-ventricular heart block, ventricular premature contractions, heart failure of the congestive type.

The daily intake of fluids was $1200 \mathrm{cc}$. Soon after admission it was necessary to remove fluid from the right pleural cavity by paracentesis and again 1 week later. These procedures relieved the dyspnoea only temporarily. The output varied between $500 \mathrm{cc}$. and $890 \mathrm{cc}$. a day. Theocalcin 3.0 grams was given. Increase in volume of urine occurred promptly amounting to $2485 \mathrm{cc}$. per day (fig. 6). In 9 days the patient lost $7.0 \mathrm{kgm}$. with disappearance of edema and diminution of ascites. After an interval of 4 days digitan 1.0 gram was given within 24 hours, followed by 0.2 gram the next day; there was no increase in the

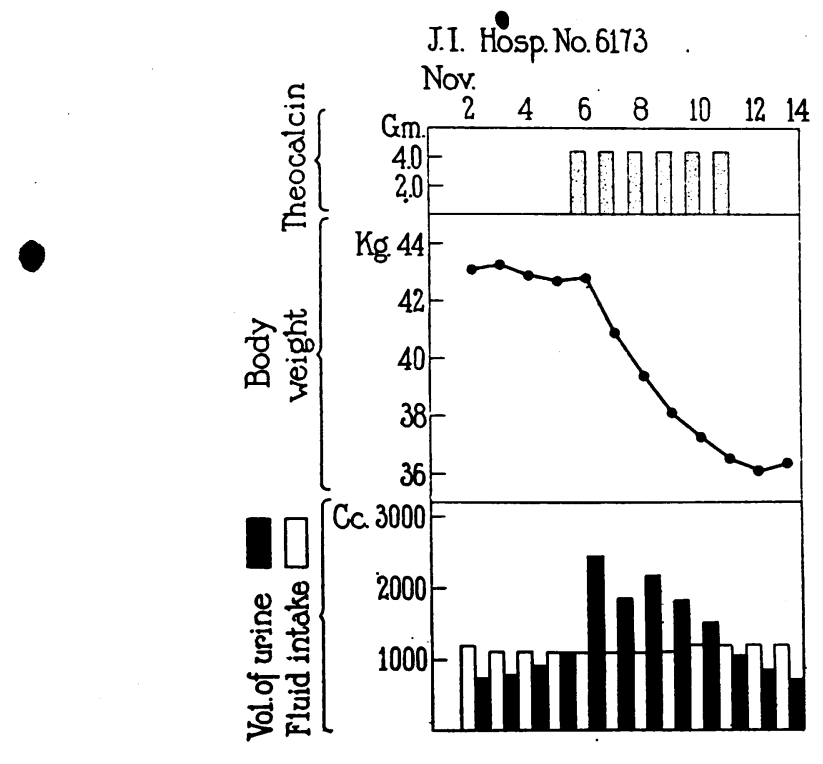

Fig. 7. Effect of Theocalcin in Case 14

See legend of figure 2

volume of urine. After it was certain that digitalis was without effect, theocalcin was given again. The output increased and remained between $800 \mathrm{cc}$. and 1200 cc. per day, and although there was a loss of $3.5 \mathrm{kgm}$. in weight in a period of 17 days, the output was only great enough to prevent further accumulation of fluid. On discontinuing theocalcin it became necessary to remove fluid from the right pleural cavity again. He was given diuretin 1.8 gram a day on 3 days, but the output of urine did not increase and he continued to gain weight. After a 2 day period of theocin administration, the output on one day rose to $1415 \mathrm{cc}$., but this was not sufficient to prevent a further gain in weight. The administration of urea $\mathbf{3 0 . 0}$ grams a day on 3 days was without diuretic effect, as was also the 
intramuscular injection of salygran $1.0 \mathrm{cc}$. The gain in weight continued, edema returned and ascites increased to such an extent that it was necessary to remove fluid $(7000 \mathrm{cc}$.) from the abdominal cavity. Digifoline (Ciba) 1.2 gram was then given, the output rising to $900 \mathrm{cc}$. to $1100 \mathrm{cc}$. a day without loss of weight. Fluid was again removed from the right pleural cavity. On administering theocalcin (3.0 grams a day) again, the output of urine increased and a loss of $3.0 \mathrm{kgm}$. of weight occurred within 6 days. Although the drug was used 3 days longer the output of urine decreased. Novasurol $1.0 \mathrm{cc}$. was then injected intramuscularily but the output still remained low. During the next 4 days when the patient received no drugs a gain in weight occurred. Digitalis lutea (Upsher Smith) 0.715 gram was then administered without increasing the output of urine. Five days later on taking theocalcin the output increased to $1220 \mathrm{cc}$. a day and the drug was continued for 11 days. Until the time of discharge from hospital the patient was given digitan 1.2 gram every 2 weeks to keep the ventricular rate slow. He received theocalcin as long as it increased the output of urine. It was then omitted to be resumed a few days later. Ascites and pleural effusion slowly reaccumulated and had to be removed frequently. During the last week of the patient's stay in hospital he received a diet free of salt. This regime, however, had no effect on the volume of urine. The patient died 3 months after leaving hospital.

Of the drugs administered to this patient, theocalcin was the only one which induced diuresis. On the first occasions diuresis was striking, but later it increased the output only to an amount which balanced the intake of fluids.

Case 7. A. G., Hospital No. 6015, was a male aged 56 years, who suffered from 4 attacks of heart failure of the congestive variety. The signs of failure were edema, ascites, right hydrothorax, and enlargement of the liver, together with dyspnoea. The systolic blood pressure measured $140 \mathrm{~mm}$. of mercury, the diastolic $100 \mathrm{~mm}$. Diagnosis: Etiological: arteriosclerosis; Anatomical: hypertrophy of the heart, chronic myocarditis, mitral insufficiency, left ventricular preponderance; Physiological: normal sinus rhythm, right intraventricular heart block, heart failure of the congestive type. The patient's intake of fluid was $1200 \mathrm{cc}$. a day. After a control period, the administration of digitan 1.3 gram induced diuresis; comparable results were observed a week later when a similar amount was given, and he lost $5.3 \mathrm{kgm}$. in 11 days. Edema disappeared, cyanosis and dyspnoea became less, but fluid was still present in the right pleural cavity. One week later digitan 1.8 gram was administered within 3 days without diuretic effect. Theocalcin 3.0 grams a day was then given. The output increased to $1440 \mathrm{cc}$. on one day and the patient lost $1.9 \mathrm{kgm}$. in 5 days (table 1), and the amount of fluid in the right pleural cavity decreased. At this time the patient was transferred to another hospital.

To this patient then theocalcin was given when he was under the influence of digitalis, the only evidence of heart failure being fluid in the right pleural cavity. Slight diuresis occurred. 
Case 8. J. M., Hospital No. 5828, was a male aged 71 years, complaining of shortness of breath of 2 months' and edema of $1 \frac{1}{2}$ months' duration. This was his first attack of heart failure. Diagnosis: Etiological: arteriosclerosis; Anatomical: chronic myocarditis, cardiac hypertrophy, aortic roughening, mitral insufficiency; Physiological: normal sinus rhythm, left ventricular preponderance, heart failure of the congestive type.

The signs of heart failure were edema, right hydrothorax, and swelling of the liver. While resting in bed and taking a restricted amount of fluid (1200 cc. per day) diuresis occurred and he became free of signs and symptoms of heart failure. The administration of digitalis did not induce diuresis, nor did diuresis occur when he was given theocalcin 3.0 grams a day for 9 days (table 1). Later, fluid reaccumulated in the right pleural cavity. There was no diuresis when theocalcin was given again and it was discontinued on the 6th day of its administration because of nausea and vomiting. Theocin 0.9 gram a day for 3 days was without diuretic effect, and also caused nausea and vomiting. Digifoline (Ciba) was given without increasing the volume of urine. Suddenly the patient developed cardiac pain; a pericardial friction rub was heard; the temperature rose; changes occurred in the form of the R-and S-waves of the electrocardiogram. We were of the opinion that occlusion of a coronary artery had occurred. The patient died 36 hours later. At autopsy the coronary arteries were found to be patent. Purulent pericarditis had taken place.

Case 9. W. H., Hospital No. 9206, was a male aged 52 years, who was admitted to hospital complaining of shortness of breath for 2 years, and edema of the legs of 2 weeks' duration. Cardiac symptoms first occurred 2 years before admission. At that time he experienced symptoms which simulated those following occlusion of a coronary artery. Since that time he had been almost completely incapacitated. The signs of heart failure were edema, right hydrothorax, and enlargement of the liver. The systolic blood pressure measured $130 \mathrm{~mm}$. mercury, the diastolic $80 \mathrm{~mm}$. Diagnosis: Etiological: arteriosclerosis; Anatomical: cardiac hypertrophy, chronic myocarditis, left ventricular preponderance, Physiological: normal sinus rhythm, heart failure of the congestive type.

The patient was given digitalis when taking $1200 \mathrm{cc}$. of fluid a day without the occurrence of diuresis. On the first day that theocalcin 4.5 grams was given the output rose from $620 \mathrm{cc}$. to $1049 \mathrm{cc}$. (table 1). At this time the patient exhibited auricular flutter, ventricular premature contractions, and intraventricular heart block. There was a rise in temperature and leucocytosis. A diagnosis of coronary occlusion was made. The patient gradually became worse and died 9 days after admission. Although theocalcin was given on the 6 days before death occurred, diuresis did not result. At autopsy the heart was found to be the seat of marked myocardial injury due to recent and old healed infarcts. There was advanced arteriosclerosis of the coronary arteries. 


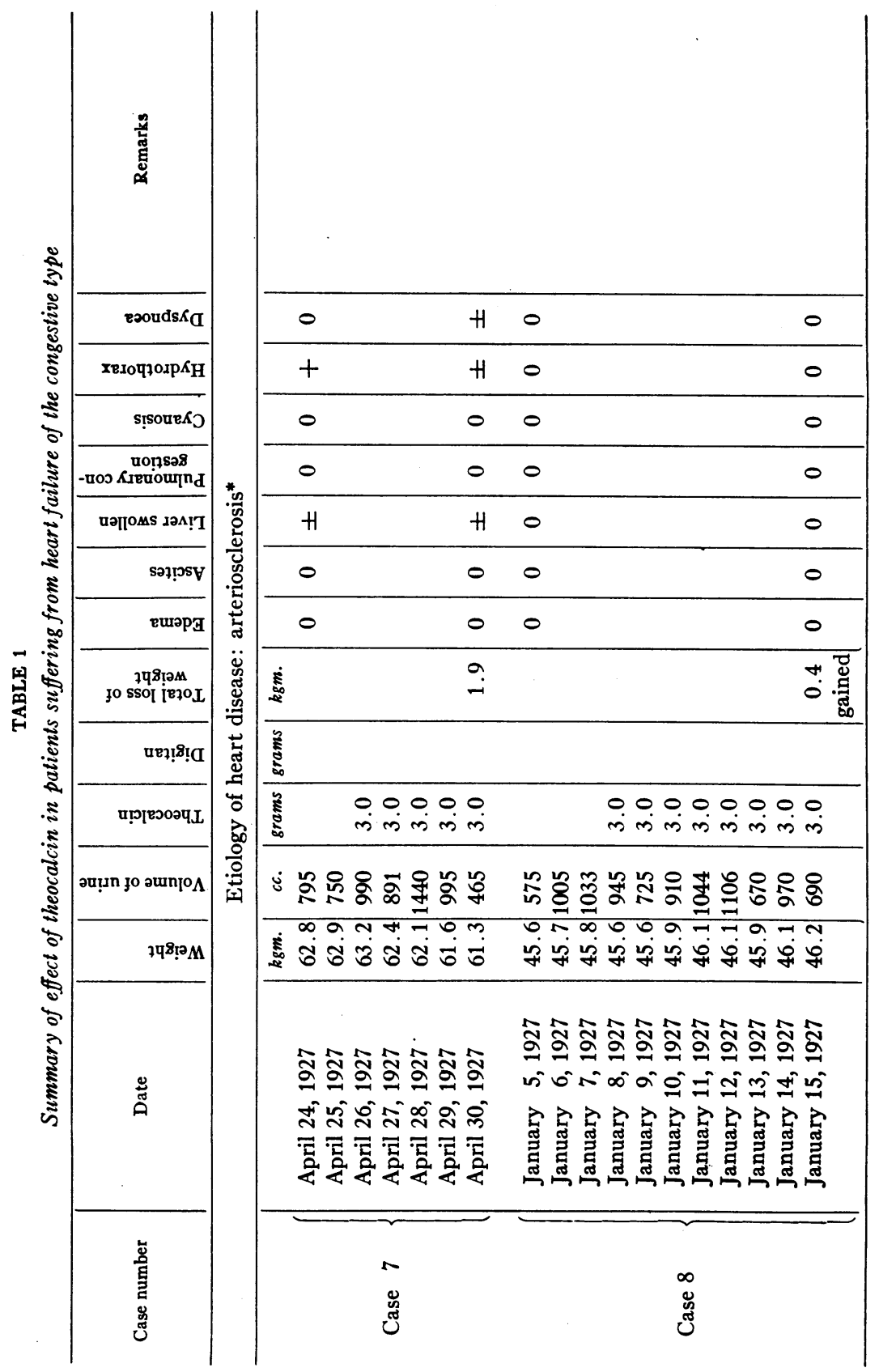




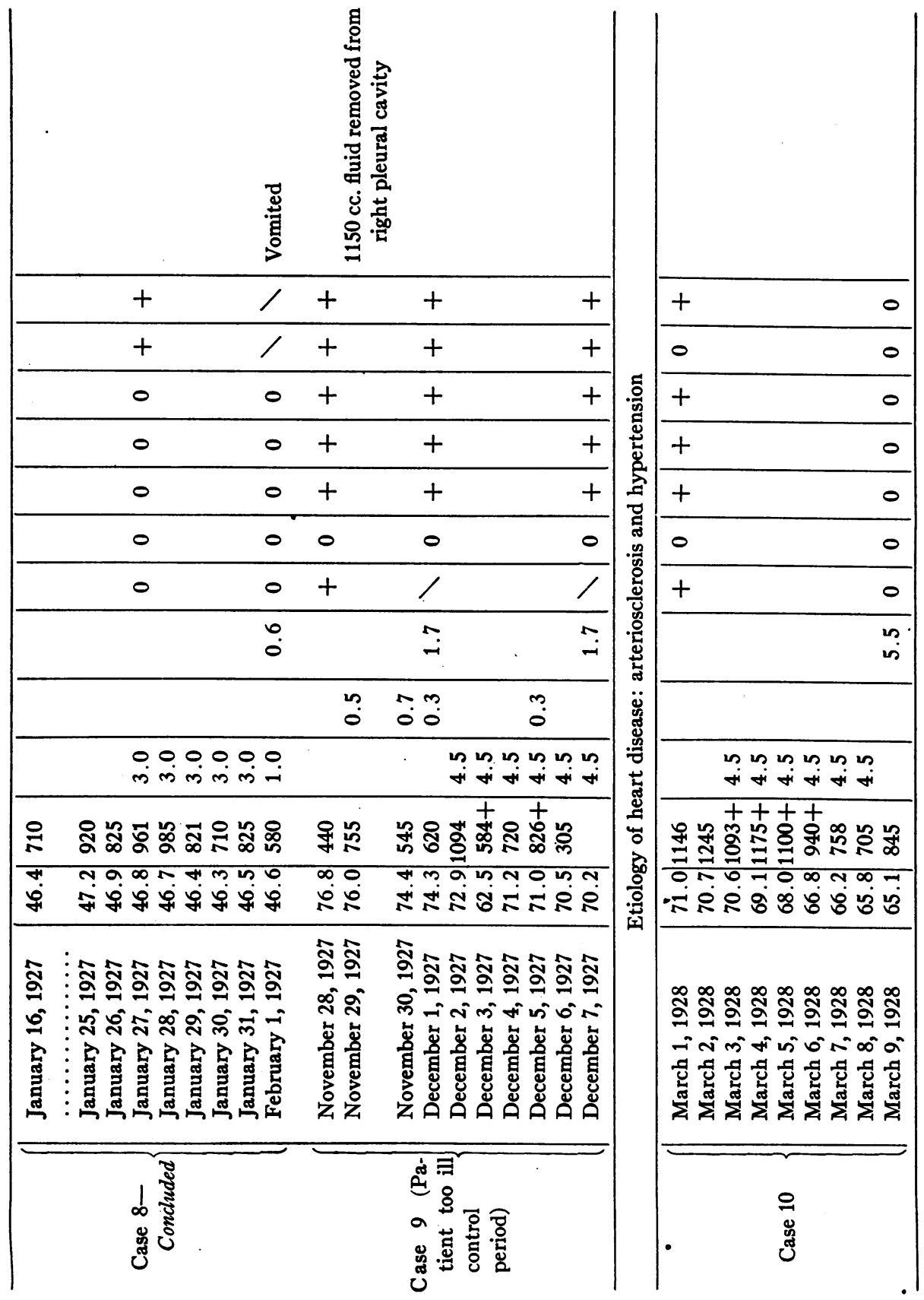




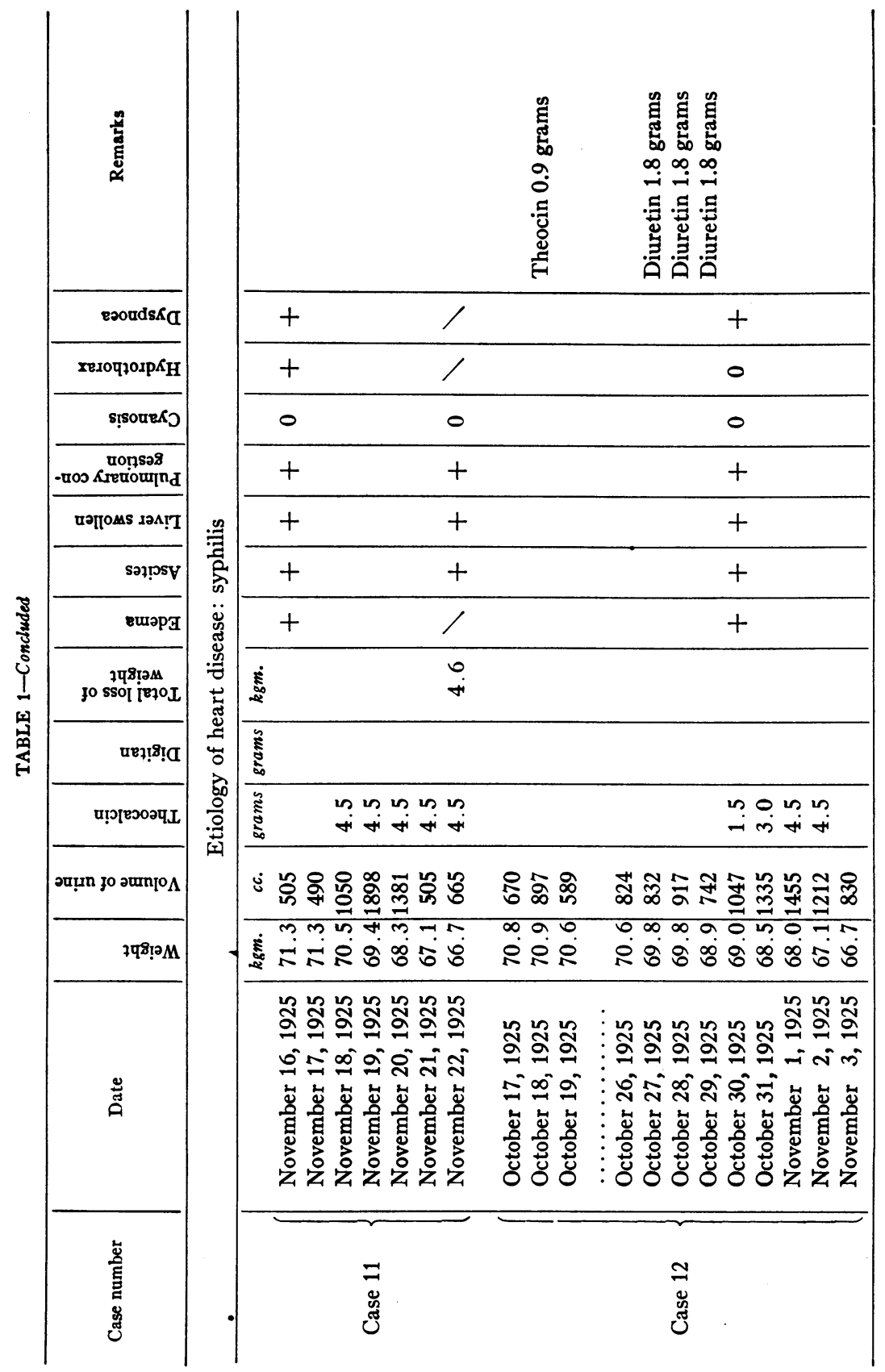




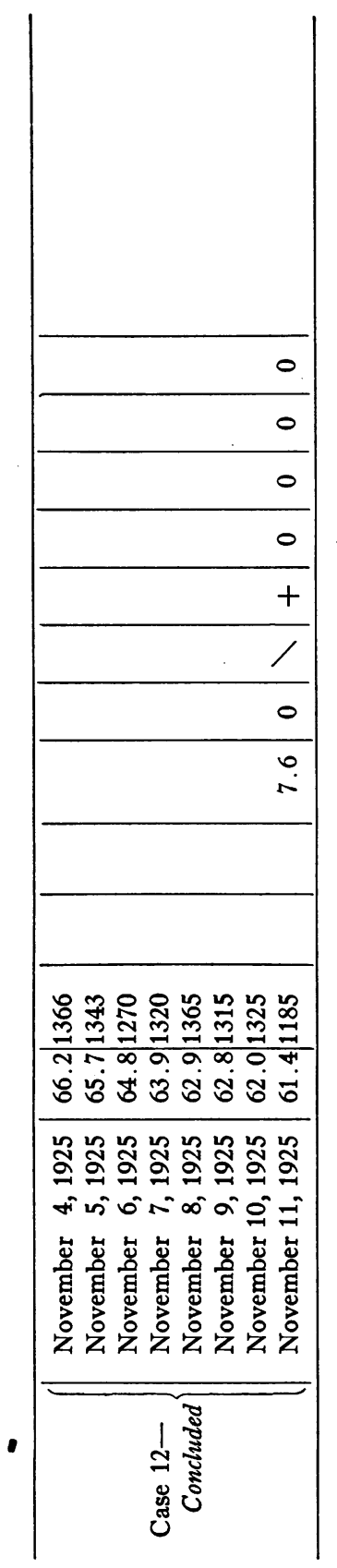

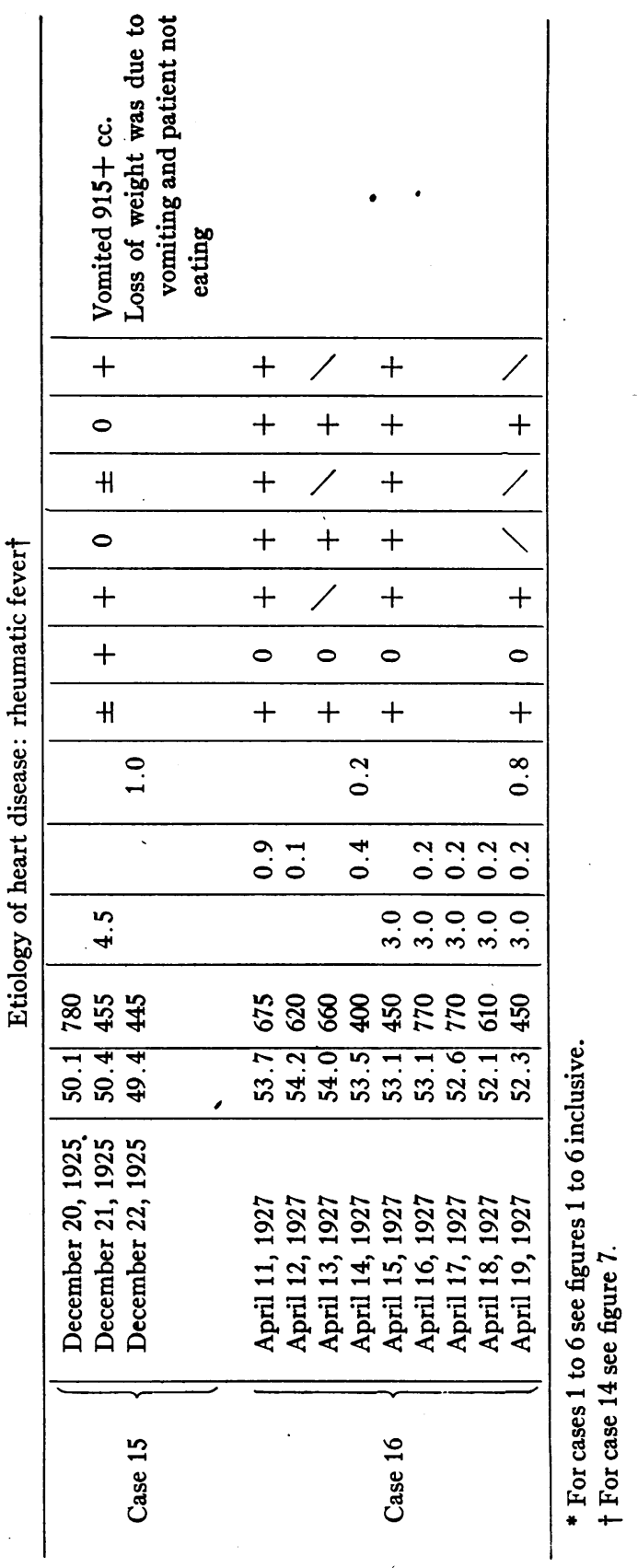


Case 10. J. F., Hospital No. 6330, was a male aged 67 years, who was admitted to hospital suffering from a first attack of heart failure. The signs and symptoms were extreme dyspnoea, cyanosis, pulmonary congestion, edema and enlargement of the liver. There was a marked degree of thickening and hardening of the peripheral arteries. The systolic blood pressure measured $230 \mathrm{~mm}$. of mercury, the diastolic $120 \mathrm{~mm}$. It was not possible to decide whether arterial hypertension or senile changes in the myocardium due to arteriosclerosis, or the combination of the two, precipitated heart failure. The electrocardiogram did not give evidence of myocardial damage. The Wassermann reaction of the blood was negative. Diagnosis: Etiological: hypertension, arteriosclerosis; Anatomical: cardiac hypertrophy, mitral insufficiency, aortic insufficiency, left ventricular preponderance; Physiological: normal sinus rhythm, auricular premature contractions, heart failure of the congestive type.

While resting in bed taking $1200 \mathrm{cc}$. of fluid a day, the patient lost $2.4 \mathrm{kgm}$. in weight and edema decreased slightly. His condition became stationary, but on receiving theocalcin 4.5 grams a day for 6 days he lost $5.5 \mathrm{kgm}$. (table 1) and became free of edema. Cyanosis and dyspnoea disappeared, the lungs were no longer congested, and the liver was no longer palpable. Diuresis occurred but its occurrence is not obvious in the fluid output chart because of lack of coöperation on the part of the patient. He was discharged in excellent condition.

Theocalcin was effective in this instance in relieving the patient of heart failure.

Case 11. O. M., Hospital No. 5439, was a man aged 48 years, suffering from a third attack of cardiac failure. An attack of rheumatic fever had occurred 13 years previously. The signs of failure were edema, ascites, fluid in the right pleural cavity and dyspnoea. The systolic blood pressure was $190 \mathrm{~mm}$. of mercury and the diastolic $70 \mathrm{~mm}$. The Wassermann reaction of the blood was positive. Diagnosis: Etiological: hypertension, rheumatic fever (inactive), syphilis; $A n a$ tomical: mitral insufficiency, aortic insufficiency, cardiac hypertrophy, left ventricular preponderance; Physiological: normal sinus rhythm, heart failure of the congestive type.

Although the fluid intake was limited to $1200 \mathrm{cc}$. a day and digitalis therapy was started, diuresis did not occur. On giving theocalcin 4.5 grams a day the output of urine increased from $490 \mathrm{cc}$. to $1898 \mathrm{cc}$. resulting in a loss of $4.6 \mathrm{kgm}$. in weight in 5 days (table 1). Accompanying this, edema and the pleural effusion decreased. Digitan 1.2 gram was given after the preliminary administration of calcium chloride intravenously without inducing diuresis. Small doses of digitan were continued. When theocalcin was given again and its use continued, the output increased, he lost weight, at the end of $2 \frac{1}{2}$ months was free of edema and of ascites, was no longer dyspnoeic, and the liver was barely palpable. Occasionally theocalcin was omitted for a few days, while digitan 1.0 to 1.2 gram was given within 24 hours every 2 to 3 weeks to keep the ventricular rate slow. Theocin was found to be without diuretic effect. The patient was free of signs of heart failure and was about to begin sitting up. Suddenly he exhibited symptoms 
which at first simulated those accompanying infarction of the lung. These were characterized by pain in the left half of the chest in front, fever, pleural friction rub and bloody sputum. There was flatness to percussion over the area and the breath sounds were absent. In the course of time these signs were heard over a larger area. X-ray photographs revealed a shadow which increased rapidly in size. Shortly afterward a mass was palpated in the region of the liver and the lymph nodes in the right axilla became enlarged. It was thought that the patient suffered from carcinoma of the lung and that metastases had occurred. The patient failed rapidly and died of general carcinomatosis $1 \frac{1}{2}$ months after the appearance of the first pulmonary symptoms. During the last weeks the administration of theocalcin maintained the volume of urine near the level of the intake.

The administration of theocalcin to this patient was followed by diuresis. It was used over a long period of time without the appearance of toxic symptoms.

Case 12. N. C., Hospital No. 5406, was a man aged 46 years, who had suffered from cardiac pain for 5 years, dyspnoea and swelling of the legs for $2 \frac{1}{2}$ years and. fluid in the abdominal cavity for 2 years. Diagnosis: Etiological: syphilis (Wassermann reaction of the blood positive); Anatomical: aortic insufficiency, perforation of aortic cusp, mitral insufficiency, chronic myocarditis, cardiac hypertrophy, left ventricular preponderance; Physiological: auricular fibrillation, heart failure of the congestive type.

The fluid intake was limited to $1000 \mathrm{cc}$. per day. Neither theocin 0.9 gram on one day nor diuretin 1.8 gram a day for 3 days initiated diuresis. When theocalcin 1.5 gram was given one day, followed by 3.0 grams, 4.5 grams and 4.5 grams. on the next 3 days the output increased to $1455 \mathrm{cc}$. and the patient began losing weight (table 1). The output of urine still continued to be greater than the fluid intake when the drug was omitted, and in 12 days the patient lost $7.6 \mathrm{kgm}$. with disappearance of edema, decrease in ascites, and loss of pulmonary congestion. Diuresis did not occur on giving digitalis. Later, following the reinstitution of theocalcin therapy, he became entirely free of ascites although the output did not increase. Later still, theocalcin was given on two occasions without increasing the output; on one of them ascites was present and on the other there were no signs of heart failure. The systolic blood pressure which measured $160 \mathrm{~mm}$. $\mathrm{Hg}$. when the patient exhibited signs of heart failure, fell to $120 \mathrm{~mm}$. when he became free of these signs. The diastolic blood pressure varied between 30 and $40 \mathrm{~mm}$. $\mathrm{Hg}$.

In this patient therefore theocalcin was effective on several occasions in initiating diuresis but later was without effect.

Case 13. J. M., Hospital No. 5810, was a male aged 50 years. The signs of heart failure were edema, hydrothorax and ascites. Diagnosis: Etiological: syphilis; Anatomical: aortitis, chronic myocarditis, cardiac hypertrophy; Physiological: normal sinus rhythm, heart failure of the congestive type. 
There was definite increase in the volume of urine coincident with the giving of theocalcin. It was given, however, too soon after the siwultaneous administration of digitalis and urea to be certain to which this action was due. The case of this patient is therefore not reported more fully.

Case 14. J. I., Hospital No. 6173, was a female aged 15 years, complaining of shortness of breath for 2 years and edema of the extremities for 4 months. She had suffered from an attack of rheumatic fever when $11 \frac{1}{2}$ years of age. There were marked edema of the extremities, ascites, enlargement of the liver and pulmonary congestion, together with dyspnoea and cyanosis. Diagnosis: Etiological: rheumatic fever (inactive, later becoming active); Anatomical: cardiac hypertrophy, mitral insufficiency, aortic insufficiency, right ventricular preponderance; Physiological: normal sinus rhythm, heart failure of the congestive type.

The intake of fluid was limited to $1200 \mathrm{cc}$. a day. After the first day in hospital the weight remained stationary, varying only slightly between $42.7 \mathrm{kgm}$. and 43.1 $\mathrm{kgm}$. On giving theocalcin 4.5 grams a day for 6 days the volume of urine increased to $2430 \mathrm{cc}$. a day, and the patient lost $6.7 \mathrm{kgm}$. in weight (fig. 7). Edema almost disappeared, ascites was no longer present, the liver was smaller, pulmonary congestion disappeared, cyanosis was less marked and dyspnoea diminished. The drug was omitted because diuresis stopped. At this time daily elevation of temperature occurred and the fever was found to recur in cycles. Five days after the last administration of theocalcin, the drug was given again because the output of urine had fallen to $400 \mathrm{cc}$. a day. When its use was continued for 13 days the output was sufficient to prevent the reappearance of marked signs of congestion. Because the ventricular heart rate was now very rapid, digitan 1.1 gram was given in 24 hours followed by a total of 0.6 gram in the next 3 days. Although the cardiac rate became slower, and the patient felt better, diuresis did not occur. She continued to receive, nevertheless, small doses of the drug because of its effect in keeping the heart rate slow. Rheumatic nodules then appeared. With the reappearance of edema and ascites the patient gained weight and the output of urine fell to between 300 and $400 \mathrm{cc}$. per day. When theocalcin 4.5 grams a day was given again the maximum daily output rose to $2225 \mathrm{cc}$. and in 5 days the patient lost $2.9 \mathrm{kgm}$. in weight. The drug was discontinued 2 days later because diuresis was not maintained. Edema disappeared but there still remained free fluid in the abdominal as well as in both pleural cavities. On this occasion there was slight nausea on the last day the drug was given. On one other occasion (one month after the last one) theocalcin 4.5 grams a day for 5 days increased the urinary output from $285 \mathrm{cc}$. or $380 \mathrm{cc}$. a day to $1420 \mathrm{cc}$., but it was not sufficient to decrease the accumulations of fluid and only $0.6 \mathrm{kgm}$. in weight was lost. Nausea recurred on the last day. During the next $3 \frac{1}{2}$ months on injecting novasurol $2.0 \mathrm{cc}$. every 3 to 4 days the output rose to $1500 \mathrm{cc}$. to $1800 \mathrm{cc}$. on the day of the injection and was sufficient to prevent an increase in body weight and the further accumulation of fluid; it was not sufficient, however, to free the patient of the signs of failure that were present. 
On 3 occasions therefore the administration of theocalcin to this patient was successful; on a fourth occasion its effect was less marked.

Case 15. T. T., Hospital No. 5471, was a female aged 23 years, exhibiting slight edema and ascites. Four attacks of heart failure of the congestive variety had occurred within 14 years. Diagnosis: Etiological: rheumatic fever (inactive); Anatomical: mitral insufficiency, aortic roughening, cardiac hypertrophy, right ventricular preponderance; Physiological: auricular fibrillation, heart failure of the congestive type.

Theocalcin 4.5 grams was given on one day without increasing the volume of urine (table 1). Nausea and vomiting occurred. Later, the administration of theocin 0.9 gram failed of effect. By means of prolonged rest in bed, combined with administration of digitalis and the restriction of the fluid intake to $1200 \mathrm{cc}$. a day, the patient slowly became free of edema and ascites.

Case 16. K. H., Hospital No. 6024, was a female aged 35 years, who had suffered from an attack of heart failure 15 months previously. The present attack was of less than one month's duration. She coughed and was very dyspnoeic. There was marked cyanosis, together with pulmonary congestion, pleural effusion; edema and enlargement of the liver were present. Diagnosis: Etiological: rheumatic fever (inactive); Anatomical: cardiac hypertrophy, pulmonary infarction, left ventricular preponderance; Physiological: auricular fibrillation, ventricular premature contractions, heart failure of the congestive type.

The intake of fluid was limited to $1200 \mathrm{cc}$. a day. When she was given digitan 1.0 gram the ventricular rate became slower, but diuresis did not occur. Theocalcin 4.5 grams a day on 5 days with small doses of digitan failed to bring on diuresis. The temperature rose, many ventricular premature contractions occurred singly and in paroxysms of ventricular tachycardia. $\bullet$ The patient became worse rapidly and died.

Case 17. R. McCl., Hospital No. 5645, was a male aged 19 years complaining of cardiac pain which was found to be associated with the occurrence of auricular premature contractions. There were no signs of heart failure of the congestive variety. The systolic blood pressure was $100 \mathrm{~mm}$. $\mathrm{Hg}$, whe diastolic $70 \mathrm{~mm}$. Diagnosis: Etiological: rheumatic fever (inactive); Anatomical: chronic myocarditis, slight cardiac hypertrophy, right ventricular preponderance; Physiological: normal sinus rhythm, auricular premature contractions, cardiac pain.

When theocalcin 4.5 grams a day was given to this patient on 4 days diuresis .did not occur (table 2).

Case 18. J. M., Hospital No. 6211, was a male aged 51 years who exhibited edema, ascites, and hydrothorax of nephritic origin. The systolic blood pressure measured $155 \mathrm{~mm}$. Hg., and the diastolic $80 \mathrm{~mm}$. The intake of fluid was limited 

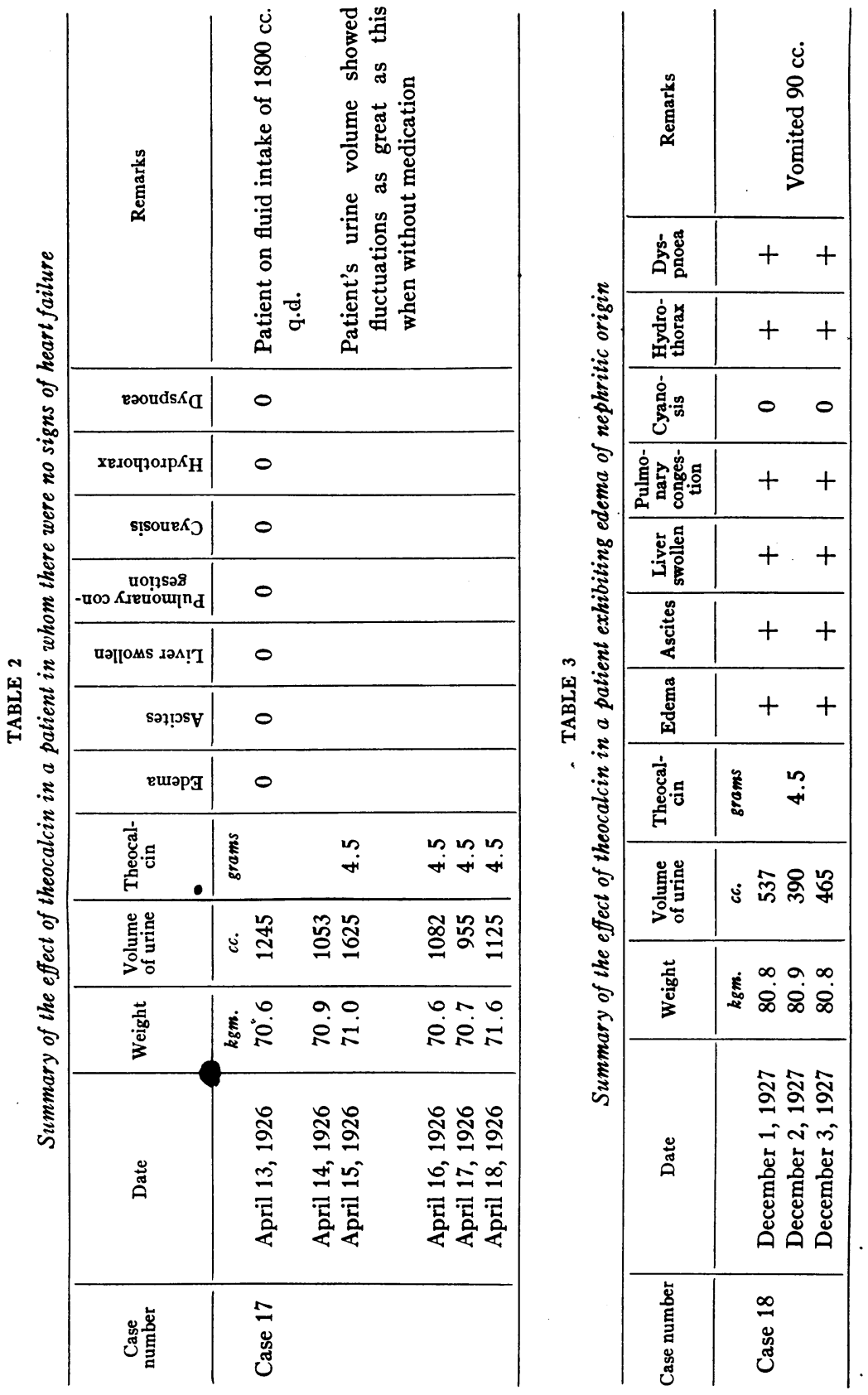
to $1200 \mathrm{cc}$. a day. The administration of theocalcin 4.5 grams caused nausea and vomiting. It was not followed by increase in output of urine (table 3 ). The exhibition of digitalis likewise did not initiate diuresis. Later, however, marked diuresis occurred when he was given a diet free of salt, and the edema, ascites and hydrothorax disappeared.

TABLE 4

Comparison of the effect of giving theocalcin with that of other diuretics

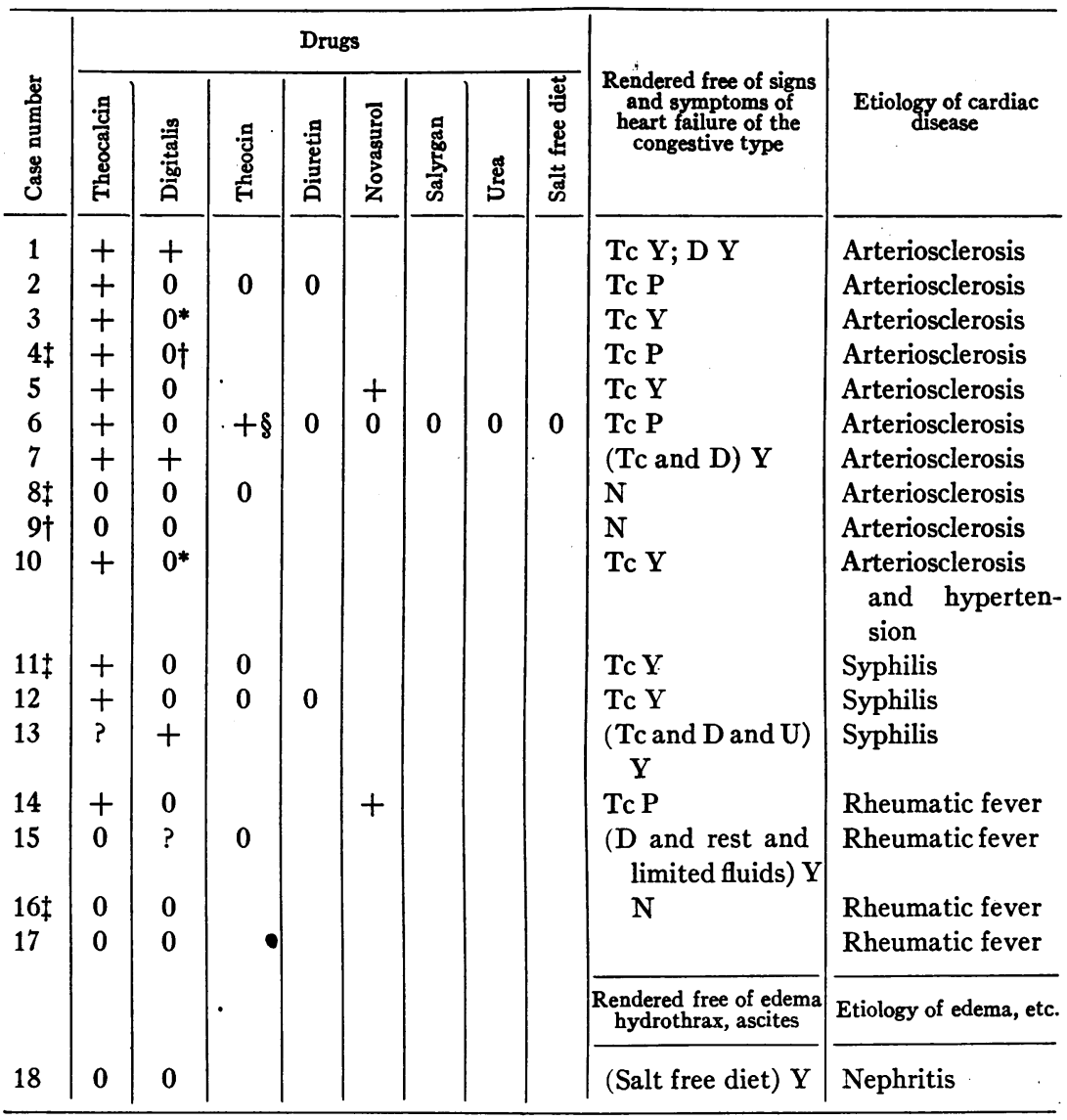

$+=$ diuresis; $0=$ no diuresis $; ?=$ unable to evaluate effect; $T c=$ theocalcin $; D=$ digitalis; $\mathrm{U}=$ urea $\mathrm{Y}=$ yes $\mathrm{N}=$ no; $\mathrm{P}=$ partially.

* The patient was without signs of heart failure of the congestive type when digitalis was given.

† On a previous admission the administration of digitalis induced diuresis.

$\ddagger$ Patient died while in hospital.

$\S$ The volume of urine increased slightly on one day only. 
The administration of theocalcin to this patient exhibiting edema, ascites and hydrothorax of nephritic origin was not followed by diuresis.

Summary of observations. Theocalcin was given to 16 patients suffering from heart failure of the congestive variety. In 10 (cases 1 , $2,3,4,5,6,10,11,12$ and 14) there was marked and in the eleventh (case 7) moderate diuresis but insufficient in this patient to free him of signs and symptoms of heart failure. In one patient (case 13) it is impossible to estimate the rôle theocalcin played because it was given simultaneously with other drugs. In 4 patients it was without diuretic effect (cases 8,9, 15 and 16). To one (case 15) it was toxic and could be given on one day only. The other two (cases 9 and 16) were terminal cases of cardiac decompensation. One (case 9) died of coronary occlusion and the third (case 16) of rapidly progressing heart failure. In the fourth patient (case 8) there was no adequate reason to account for its not being effective. He died later of purulent pericarditis.

Theocalcin was without diuretic effect in one patient (case 17) without signs of heart failure of the congestive type as well as in a second patient (case 18) exhibiting edema and ascites of nephritic origin.

\section{DISCUSSION}

Following the administration of theocalcin to 16 patients with heart failure of the congestive type diuresis occurred in 11 (69 per cent). In 2 of the other 5 patients there were reasons for the ineffectiveness of the drug. In 8 of the 11, diuresis was sufficient to free the patients of the signs of heart failure; in 2 it was partially effective, and in one it is impossible to estimate the part it played. It was without diuretic effect in one patient in whom there were no signs of congestion. Increase in the volume of urine did not occur, furthermore when it was given to a patient exhibiting edema of nephritic origin.

An attempt was not made in all instances to compare the effectiveness of theocalcin with that of other diuretics, but in several cases this was possible. Digitalis was effective as a diuretic in only 3 of the 16 patients (cases 1, 7 and 13), and so was theocalcin. In 3 other patients (cases 2,11 and 12) theocalcin was effective but theocin 
was not and in a fourth neither theocin nor diuretin acted. In two patients (cases 6 and 12) theocalcin was effective, although diuretin was not. In one patient (case 5) novasurol induced slight diuresis when theocalcin ceased to be useful. In the case of one patient (case 6) theocalcin was effective although all other measures failed. Theocalcin was in short by far the most effective diuretic used in the treatment of this series of patients.

It is not possible to analyze our data for the purpose of ascertaining the type of patient in which this drug is most effective, since most of the patients were of the arteriosclerotic group. Seven of 9 such patients exhibited diuresis when theocalcin was given. Of the 3 (cases 14, 15 and 16) in whom cardiac disease was of rheumatic origin, it was effective in only one (case 14). These observations resemble Marvin's (8) who was of the opinion that patients suffering from arteriosclerosis respond much more readily not only to digitalis but also to theobromine diuretics than do those of the rheumatic group. Of the three patients in whom syphilis may have been the etiological factor responsible there was increase in the volume of urine in two.

Presumably the action of theocalcin like that of the other xanthine diuretics, is directly on the kidneys. We undertook no studies, however, to discover the mechanism by which this drug acts. Whether its advantage over the other theobromine diuretics is to be attributed to the presence of the calcium ion is unknown. When calcium salts alone are given in the treatment of heart failure of the congestive variety (Stewart (9) and (10)) marked diuresis occurs rarely on the oral administration and not at all when it is given intravenously, nor is its effectiveness augmented when given together with digitalis.

Theocalcin was found less irritating to the stomach than theocin and diuretin, due perhaps to its being less soluble than these drugs and hence more slowly absorbed. In only 4 patients did nausea and vomiting occur. These symptoms were observed, however, only when diuresis did not take place (cases 8,15 and 17) or when the drug was given after ceasing to be effective (case 14). To those patients who have recovered from heart failure and in whom the water balance is maintained by its use, it may be given daily for months without the occurrence of untoward symptoms. It was diuretic when given alone; 
the administration of digitalis simultaneously did not enhance its diuretic effect. It is not intended to give the impression that it takes the place of digitalis where digitalis is effective as a diuretic, nor does it take its place in auricular fibrillation, nor indeed in certain patients exhibiting a normal rhythm to whom digitalis is given to slow the ventricular rate even though diuresis does not occur. We usually supplement the drug treatment of heart failure of the congestive type with the restriction both of the fluid intake and of the ingestion of sodium chloride. Occasionally diuresis occurs by the use of these measures alone. There is at present no means of ascertaining beforehand which drug will work; the test must be made separately in each patient. Theocalcin was, however, by far, the most effective diuretic administered in this group.

\section{SUMMARY}

1. Theocalcin given by mouth in doses of 1.0 to 1.5 gram three times a day induced marked diuresis in the majority of patients suffering from heart failure of the congestive type.

2. It was effective when other therapeutic agents failed and it appeared to be more effective than theocin and diuretin.

3 . Toxic symptoms (nausea and vomiting) occurred infrequently during its administration and were transient. It appeared to be more easily tolerated than theocin and diuretin.

4. Diuresis usually begins during the first 24 hours of administration, but it may not reach a maximum until after it has been given for several days.

5. The drug can be given as long as diuresis lasts. It may be given as long as it maintains the output of urine near the fluid intake.

\section{BIBLIOGRAPHY}

1. Basch, Erich, Die Therapie der Gegenwart, 1924, lxv, N.F. xxvi, 398. Zur therapeuti.chen Beeinflussung der essentiellen Hypertonie mit CalciumDiuretin.

2. Kaiser, K., Klin. Wchnschr., 1925, iv, 1574. Über Calcium-Diuretin.

3. Askanazy, S., Münch. Med. Wchnschr., 1925, lxxii, 646. Über Jodkalziumdiuretin.

4. Matthes, M., Med. Klinik, 1925, xxi, 271. Die Hypertonie. 
5. Fahrenkamp, K., Med. Klinik, 1924, xx, 179. Ủber den Wert der Blutdruckkurve für Prognose und Therapie.

6. Selig, A., Wien. Med. Wchnschr., 1926, lxxvi, 895. Therapeutische Erfahrungen mit Kalzium-Diuretin.

7. Stewart, H. J., Am. Heart J., 1928, iv, 227. Pleural Effusion Localized in an Interlobar Space. Report of a Case of Heart Failure Together with Autopsy.

8. Marvin, H. M., J. Clin. Invest., 1927, iii, 521. Digitalis and Diuretics in Heart Failure with Regular Rhythm, with Especial Reference to the Importance of Etiologic Classification of Heart Disease.

9. Stewart, H. J., Am. Heart J., 1929, iv, 512. The Oral Administration of Calcium Chloride in Congestive Heart Failure.

10. Stewart, H. J., Am. Heart J., 1929, iv, 646. The Use of Calcium Chloride Given Intravenously in Congestive Heart Failure. 